\title{
PENGARUH VARIASI KEMIRINGAN FLUSHING CONDUIT TERHADAP VOLUME PENGGELONTORAN SEDIMEN DI WADUK (UJI EKSPERIMENTAL)
}

\author{
Muh. Adnan ${ }^{(1}$ dan Muflihin ${ }^{(2}$ \\ ${ }^{1)}$ Universitas Muhammadiyah Makassar, Indonesia \\ Email :Adnan2013@engineer.com \\ ${ }^{2)}$ Universitas Muhammadiyah Makassar, Indonesia \\ Email:muflihinsipil@gmail.com
}

\begin{abstract}
Abstrak
Penelitian ini bertujuan untuk mengetahui pengaruh penggelontoran sedimentasi dengan sistem flushing conduit jika menggunakan pipa dengan kemiringan yang bervariasi. Karakteristik sedimen yang digunakan dalam penelitian ini adalah pasir sedang berdasarkan skala wentworth dari hasil analisa saringan. Dari hasil penelitian menunjukan jumlah sedimen yang tergelontor untuk $Q_{1}$ yaitu pada kemiringan pipa (I) $3^{\circ}$ jumlah volume gelontor $\left(v_{g}\right) 0,0043 \mathrm{~m}^{3}$, kemiringan pipa $(I) 6^{\circ}$ jumlah Volume tergelontor $\left(v_{g}\right) 0,0048 \mathrm{~m}^{3}$ dan pada kemiringan pipa (I) $9^{\circ}$ jumlah volume gelontor $\left(v_{g}\right)$ yaitu 0,0055 $\mathrm{m}^{3}$. Kinerja Flushing Conduit menunjukan semakin miring pipa Flushing Conduit $(I)$ volume gelontor $\left(v_{g}\right)$ cenderung meningkat akibat bertambahnya kecepatan aliran dalam pipa. Mekanisme kerja flushing conduit terbagi atas tiga tahapan yaitu memberikan tekanan sehingga terjadi fluidasi, proses penghisapan endapan sedimen masuk kedalam pipa akibat fluktuasi debit dan tekanan, serta transportasi sedimen dalam pipa.
\end{abstract}

kata kunci : Waduk, Sedimentasi, Flushing Conduit.

\begin{abstract}
This study aims to determine the effect of sedimentation with a flushing conduit system when using a pipe with varying slope. The sediment characteristic used in this research is the medium sand based on goworth scale from the result of filter analysis. The results showed that the amount of sediment that was flushed for Q1 was on the slope of the pipe (I) $3^{\circ}$ the amount of gelontor volume $(\mathrm{vg}) 0,0043 \mathrm{~m} 3$, the slope of the pipe (I) $6^{\circ}$ the volume amount was flushed (vg) 0,0048 $\mathrm{m} 3$ and on the slope pipe (I) $9^{\circ}$ the volume amount of gelontor $(\mathrm{vg})$ is $0.0055 \mathrm{~m} 3$. Flushing Conduit performance shows that the sloping pipe Flushing Conduit (I) volume of gelontor (vg) tends to increase due to the increase of flow velocity in the pipe. Working mechanism of flushing conduit is divided into three stages, namely to provide pressure so that fluidation occurs, sediment sediment absorption process into the pipe due to fluctuations in flow and pressure, as well as sediment transport in the pipeline.
\end{abstract}

keywords: DAM, Sedimentation, Flushing Conduit. 


\section{PENDAHULUAN}

Waduk merupakan tempat pada permukaan tanah yang dimaksudkan untuk menyimpan dan menampung air saat terjadi kelebihan air pada musim hujan, kemudian kelebihan tersebut dimanfaatkan untuk berbagai keperluan seperti irigasi, PLTA, air bersih dan lain-lain.

Sedimen yang terdapat di dasar waduk biasanya berasal dari endapan sedimen yang terbawa oleh aliran menuju waduk, aliran tersebut yang banyak mengandung sedimen disimpan sementara dalam volume pengendalian banjir di atas elevasi air normal cukup lama, sehingga sebagian dari sedimen akan mengendap pada elevasi dasar kolam pengendali banjir.

Usaha yang bisa dilakukan untuk mengatasi permasalahan sedimentasi didalam saluran floodway adalah dengan melakukan pembilasan atau penggelontoran sedimen secara hidrolis (hydraulic flushing). penggelontoran sedimen secara hidraulis (Hydraulic flushing) adalah cara yang lebih baik untuk mengembalikan kapasitas reservoir bila dibandingkan dengan cara lain seperti penggalian atau pengerukan secara manual (Dreedging) sehingga konsep flushing conduit (penggelontoran sedimen dalam pipa) adalah solusi yang tepat dalam pengendalian sedimen yang ramah lingkungan dan relatif murah.

\section{Waduk}

Waduk adalah tempat pada permukaan tanah yang dimaksudkan untuk menyimpan dan menampung air saat terjadi kelebihan air pada musim hujan agar dapat digunakan untuk berbagai keperluan seperti irigasi, pembangkit listrik tenaga air, penyediaan air baku dan lain-lain.

\section{Kapasitas Waduk}

Kapasitas waduk saat direncanakan berdasarkan perhitungan volume tampungan air tanpa adanya sedimentasi. Namun seiring berjalannya waktu pengoperasian waduk terjadi pendangkalan kapasitas waduk akibat laju sedimentasi.

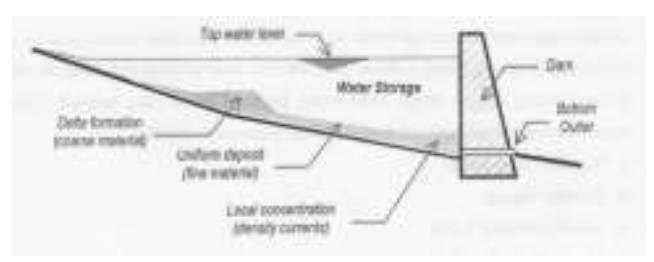

\section{Gambar 1. Berkurangnya kapasitas Waduk}

kapasitas waduk secara umum dibedakan menjadi tiga yaitu :
a) Kapasitas mati (dead storage)
b) Kapasitas pelayanan (Active Storage)
c) Kapasitas total 
Umur pelayanan waduk merupakan fungsi dari volume tampungan aktif (Ilyas et al., 1991). Semakin menyusut volume tampungan aktif menandakan semakin pendek umur pelayanan waduk.

\section{Mekanisme Gerakan Sedimen}

Mekanisme pengangkutan sedimen butir-butir tanah yang dibawah dalam air yang mengalir dapat digolongkan menjadi beberapa bagian, yaitu:

a) Wash load atau sedimen bersih

b) Suspended load transport atau angkutan sedimen melayang.

c) Salation load transport atau angkutan sedimen loncat.

d) Bed load transport atau angkutan sedimen dasar.

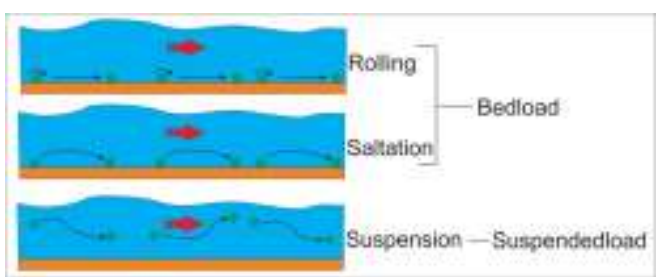

Gambar 2. Ragam gerakan sedimen dalam air

\section{Disitribusi Ukuran Butir Sedimen}

Tabel 1: Klasifikasi ukuran butir sedimen menurut \begin{tabular}{ccc} 
skala & & Wentworth \\
\hline \multirow{3}{*}{ Kerangkal } & & Diameter partikel (mm) \\
& Sangat besar & $4096-2048$ \\
& Besar & $2048-1024$ \\
& Sedang & $1024-512$ \\
Kerakal & Kecil & $512-256$ \\
\hline \multirow{3}{*}{ Koral (Kerikil besar) } & Besar & $256-128$ \\
& Kecil & $128-64$ \\
\hline \multirow{2}{*}{ Kerikil } & Sangat besar & $64-32$ \\
& Kasar & $32-16$ \\
& Sedang & $16-8$ \\
& Halus & $8-4$ \\
\hline \multirow{2}{*}{ Pasir } & & $4-2$ \\
& Sangat besar & $2-1$ \\
& Kasar & $1-0,5$ \\
\hline Lumpur & Sedang & $0,5-0,25$ \\
& Halus & $0,25-0,125$ \\
& Sangat Halus & $0,125-0,062$ \\
\hline \multirow{3}{*}{ Lempung } & Kasar & $0,062-0,031$ \\
& & \\
\hline & Sedang & $0,031-0,016$ \\
& Halus & $0,016-0,008$ \\
& Sangat Halus & $0,008-0,004$ \\
\hline Kasar & $0,004-0,002$ \\
& Sedang & $0,002-0,001$ \\
& Halus & $0,001-0,0005$ \\
& Sangat Halus & $0,0005-0,00024$ \\
\hline
\end{tabular} Sumber : Muhammad Arsyad Thaha (2006)

\section{Penggelontoran Sedimen Dengan Metode Flushing}

Metode flushing counduit atau pengurasan melalui pipa dengan memanfaatkan fluktuasi tekanan untuk mengusik endapan sedimen sehingga terfluidasi, dan selanjutnya terhisap ke dalam pipa melalui lubang kecil kemudian terjadi transpor endapan sedimen dalam pipa.

\section{Perbedaan Mekanisme kerja Fluidasi dengan flushing Conduit}

Perbedaan antara metode kerja fluidisasi dengan flushing conduit dapat dilihat dari tabel berikut : 
Tabel 2 Perbedaan metode kerja fluidasi dengan flushing conduit

\begin{tabular}{lll}
\hline No. & \multicolumn{1}{c}{ Metode Fluidasi } & \multicolumn{1}{c}{ Metode flushing conduit } \\
\hline 1. & $\begin{array}{l}\text { Mengendalikan aliran permukaan } \\
\text { mengalirkan sedimen ke daerah } \\
\text { yang lebih dalam }\end{array}$ & $\begin{array}{l}\text { Mengendalikan aliran dalam pipa } \\
\text { untuk mengelontorkan sedimen } \\
\text { ke daerah lebih dalam }\end{array}$ \\
\hline $\begin{array}{l}\text { Mengandalkan pancaran jet } \\
\text { melalui lubang perforasi untuk } \\
\text { mengusik dan mengangkat } \\
\text { sedimen }\end{array}$ & $\begin{array}{l}\text { Mengandalkan hisapan sedimen } \\
\text { melalui lubang isap ke dalam pipa } \\
\text { dan transpor sedimen dalam pipa }\end{array}$ \\
\hline 3. & Membutuhkan tekanan yang besar & $\begin{array}{l}\text { Membutuhkan tekanan fluktuaktif } \\
\text { yang relatif besar. }\end{array}$ \\
\hline 4 & $\begin{array}{l}\text { Membutuhkan debit yang relatif } \\
\text { besar }\end{array}$ & $\begin{array}{l}\text { Membutuhkan debit yang relatif } \\
\text { besar }\end{array}$ \\
\hline 5. & $\begin{array}{l}\text { Sistem pengaliran dilakukan } \\
\text { dengan pengaliran bebas }\end{array}$ & $\begin{array}{l}\text { Sistem pengaliran dilakukan } \\
\text { dengan pengaliran bertekanan } \\
\text { fluktuatuf }\end{array}$ \\
\hline 6. & $\begin{array}{l}\text { Tekanan dsalam pipa harus lebih } \\
\text { besar daripada di luar pipa }\end{array}$ & $\begin{array}{l}\text { Tekanan dalam pipa harus lebih } \\
\text { rendah dari pada luar pipa }\end{array}$ \\
\hline
\end{tabular}

Sumber : Amrullah (2011)

\section{Aliran Dalam Saluran Tertutup (PIPA)}

Aliran dalam pipa berfungsi untuk memindahkan fluida dari suatu tempat ke tempat yang lain.

Perbedaan mendasar antara aliran pada saluran terbuka dan saluran tertutup (aliran pada pipa) adalah adanya permukaan yang bebas dan (hampir selalu) berupa udara pada saluran terbuka. Jadi seandainya pada pipa alirannya tidak penuh hingga masih ada rongga yang berisi udara maka sifat dan karaktersitik alirannya sama dengan aliran pada saluran terbuka (Kadoatie 2002: 215)

\section{Aliran Laminer dan Turbulen}

Secara garis besar pola aliran dalam pipa terbagi menjadi tiga yaitu laminer, turbulen, dan transisi.

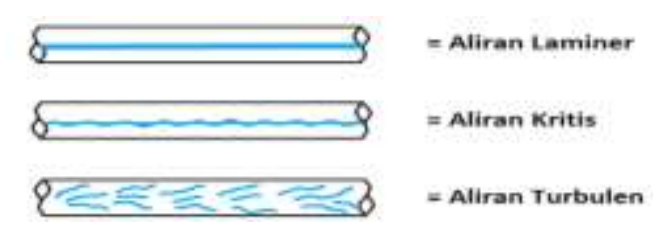

\section{Gambar 3. Pola aliran laminar, turbulen dan transisi.}

Menurut hasil percobaan Reynold, untuk membedakan apakah aliran itu turbulen atau laminer dapat menggunakan bilangan tak berdimensi yang disebut dengan bilangan Reynold. Bilangan ini dihitung dengan persamaan berikut:

$\operatorname{Re}=\frac{p v D}{\mu}=\frac{V D}{v}$.

Dimana:

$\mathrm{Re}=$ Bilangan Reynold (tak berdimensi)

$\mathrm{V}=$ Kecepatan rata-rata $(\mathrm{ft} / \mathrm{s}$ atau $\mathrm{m} / \mathrm{s}$ )

$\mathrm{D}=$ Diameter pipa (ft atau $\mathrm{m}$ )

$\mathrm{v}=$ Viskositas kinematik $\left(\mathrm{m}^{2} / \mathrm{s}\right)$

\section{Prinsip Dasar Transpor Sedimen Dalam} Pipa

Transpor sedimen dalam pipa diperlukan dalam bidang pemindahan endapan lumpur dan pengerukan (dredging). Manfaat sistem ini dalam kedua bidang tersebut adalah untuk memindahkan sedimen/endapan pada minimum head loss tanpa pengendapan. Aspek penting dari syistem ini adalah bagaimana memprediksi head loss dan kecepatan minimum atau kecepatan kritis agar supaya pipa terhindar dari pengendapan. (Amrullah, 2010). 


\section{METODE PENELITIAN}

\section{Lokasi dan Waktu Penelitian}

Penelitian ini dilakukan di Laboratorium Fakultas Teknik Universitas Muhammadiyah Makassar.

\section{Jenis Penelitian}

Jenis penelitan yang digunakan adalah eksperimental, dimana penelitian tersebut dibuat dan dirancang sendiri oleh peneliti dengan berpedoman pada literaturliteratur yang berkaitan dengan flushing conduit, serta adanya kontrol dengan tujuan untuk mengetahui sebab akibat dari penggelontoran sedimen serta berapa besar pengaruh penggelontoan terhadap variasi kemiringan pipa flushing.

\section{Tahap Penelitian}

\section{Persiapan}

Tahap pertama persiapan : Studi literatur dilakukan untuk mencari sumber data dan informasi yang akan dimuat sebagai referensi teori dalam melakukan penelitian ini (Flushing Conduit) serta melakukan persiapan pembuatan model di Laboratorium dan mempersiapan alat dan bahan untuk pembuatan saluran.

\section{Perancangan Model}

$$
\text { Perancangan model untuk }
$$
penelitian dilakukan terlebih dahulu untuk perancangan model untuk penelitian Flushing Conduit yang lebih jelas sehingga dalam penerapan dilapangan dapat berjalan sesuai rencana.

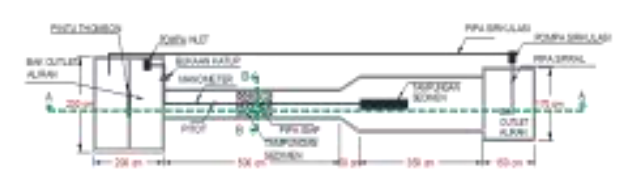

\section{Gambar 4. Denah Flushing Conduit}
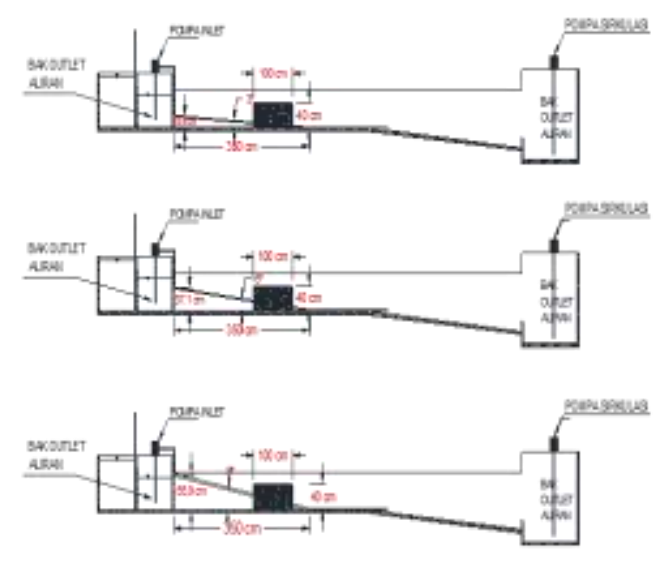

Gambar 5. Model Variasi Kemiringan Pipa Flushing

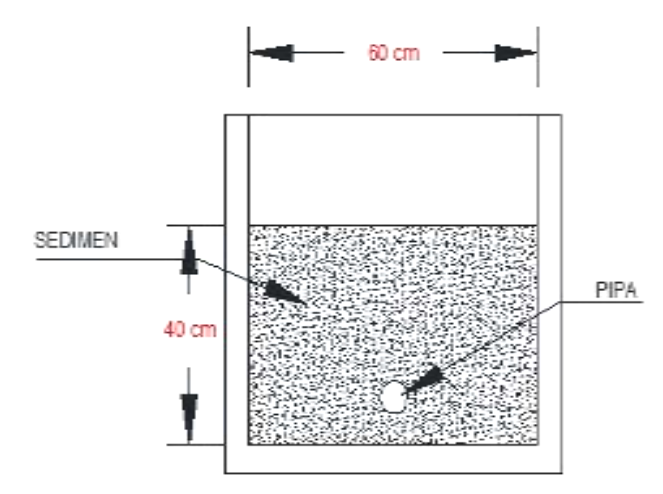

Gambar 6. Model Sedimen 


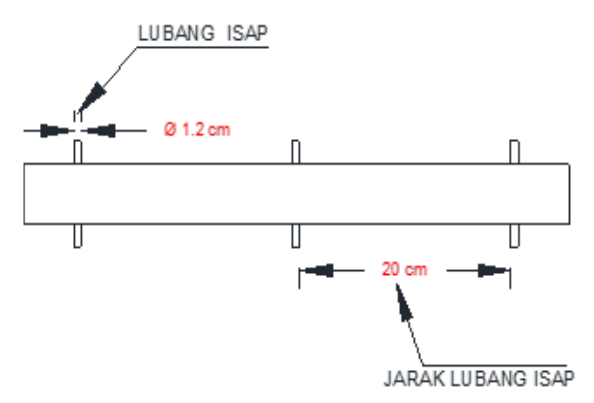

\section{Gambar 7. Detail Pipa Isap}

\section{Langkah-Langkah Penelitian}

Langkah-langkah

dalam melakukan percobaan dalam penelitian:

a) Persiapan area di laboratorium Fakultas Teknik Universitas Muhammadiyah Makassar.

b) Persiapan alat dan bahan yang digunakan selama penelitian seperti linggis, cangkul, sekop, pipa PVC 2 Inch, box penampung sedimen berukuran 30x30 cm, peralatan bengkel, pompa air, stopwatch, manometer.

c) Alat dan bahan disusun serta dirangkai sesuai dengan bentuk dan ukuran yang telah ditentukan dalam perancangan model.

d) Percobaan awal dilakukan untuk mengetahui kisaran variabel dan kemampuan alat.

e) Menjalankan pompa air dengan mengalirkan air dan sedimen dalam pipa sesuai debit dan ketebalan sedimen yang ditentukan.

f) Pengamatan kondisi sedimen dimulai terhisap sedimen dan menjalankan stop watch untuk mencatat waktu dan membaca tekanan yang terjadi.

g) Setelah variasi dan pembacaan tekanan selesai, selanjutnya mengukur besarnya sedimen yang tergelontor.

h) Hasil pengukuran sedimen yang tergelontor menjadi data jumlah sedimen endapan yang tergelontor.

i) Prosedur ini dilakukan dengan beberapa kali percobaan dimulai dari kemiringan pipa $3^{\circ}, 6^{\circ}$ dan $9^{\circ}$ untuk dijadikan bahan perbandingan.

\section{Flow Chart Penelitian}

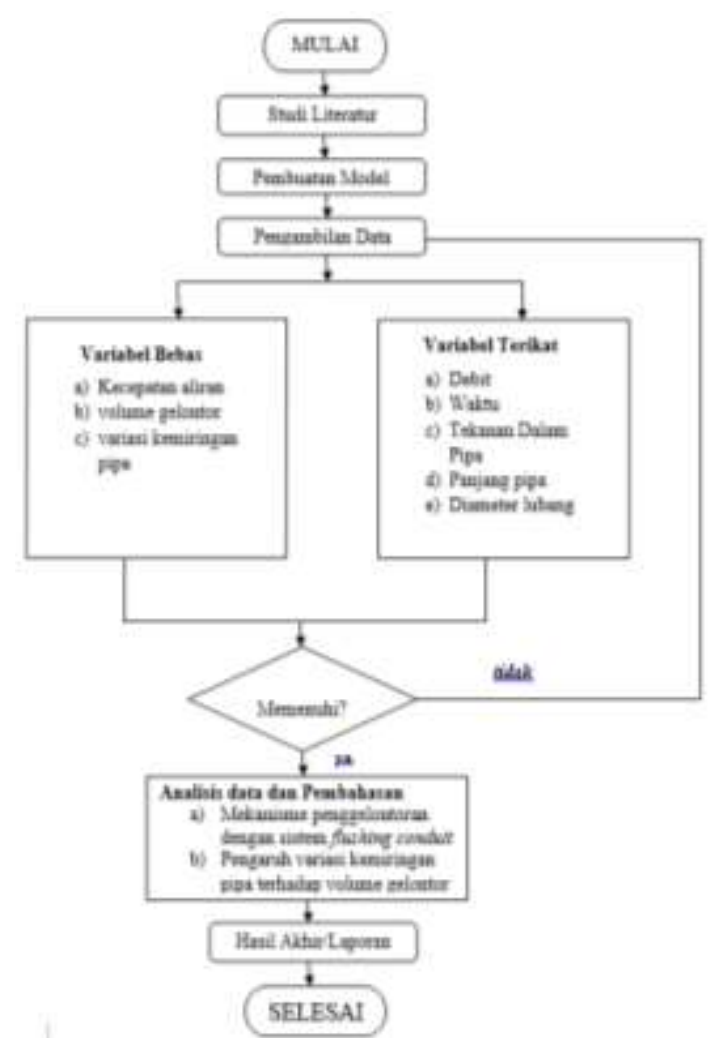

Gambar 8. Flow Chart Penelitian 


\section{HASIL DAN PEMBAHASAN}

\section{Karakteristik Sedimen}

Karakteristik sedimen yang digunakan dalam penelitiuan ini adalah Pasir sedang, sesuai dengan hasil pemeriksaan ukuran butir dengan uji saringan dan gradasi ukuran butir, yang disajikan pada gambar dan tabel berikut.

Tabel 3 Data analisa saringan

\begin{tabular}{|c|c|c|c|c|c|}
\hline \multirow{2}{*}{$\begin{array}{l}\text { sanuges } \\
\text { peil }\end{array}$} & \multirow{2}{*}{$\begin{array}{l}\text { Dameler } \\
\text { (inney) }\end{array}$} & \multirow{2}{*}{$\begin{array}{l}\text { aecut Tortahan } \\
\text { (intai) }\end{array}$} & \multirow{2}{*}{ 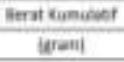 } & \multicolumn{2}{|c|}{$\operatorname{Venem}|\nabla|$} \\
\hline & & & & fartahas & whas \\
\hline 4 & $4 \pi$ & 4 & 4 & 8.4 & 78.6 \\
\hline 1 & 2,3e & $n$ & $n$ & $m$ & 20.3 \\
\hline in & 1,13 & 230 & 113 & 11,3 & 567 \\
\hline 30 & 0.55 & 97 & 190 & A & 35 \\
\hline 50 & $1029 ?$ & 49 & 363 & 863 & 18,7 \\
\hline 100 & IL) & 13 & 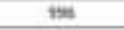 & mos & 124 \\
\hline 200 & 0034 & 4 & 1000 & 100 & a \\
\hline Pan & $=$ & 0 & 1000 & 200 & 0 \\
\hline
\end{tabular}

Sumber:Hasil Analisa Saringan

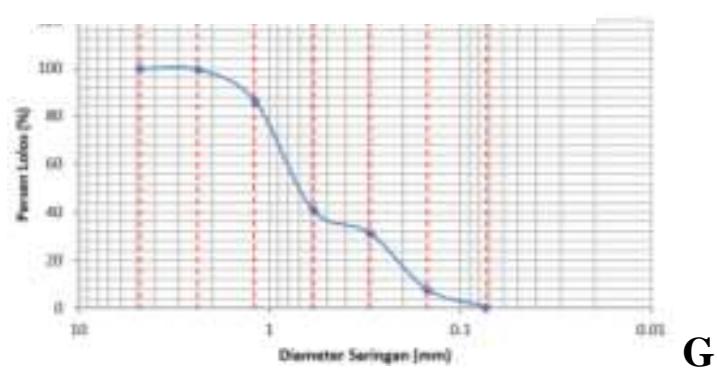

ambar 9. Gradasi ukuran butiran sedimen (sampel)

Pengaruh variasi kemiringan terhadap volume gelontor

Berdasarkan hasil data data yang diperoleh maka dapat disimpulkan bahwa
Pengaruh kemiringan (I) adalah salah satu faktor yang mempengaruhi jumlah sedimen yang tergelontor dalam proses pengurasan metode flushing conduit.

Tabel 4. Hubungan antara kemiringan pipa flushing terhadap volume gelontor. Q1=0,0030 m3/dtk

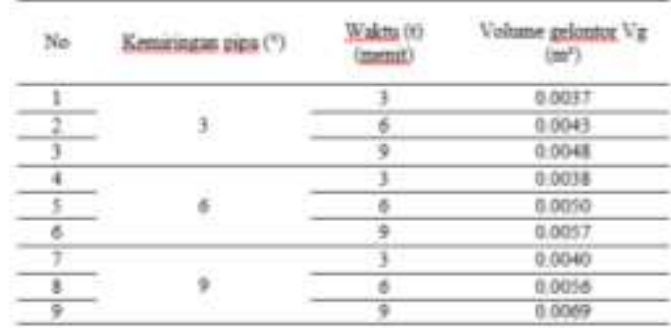

Sumber:Hasil Perhitungan

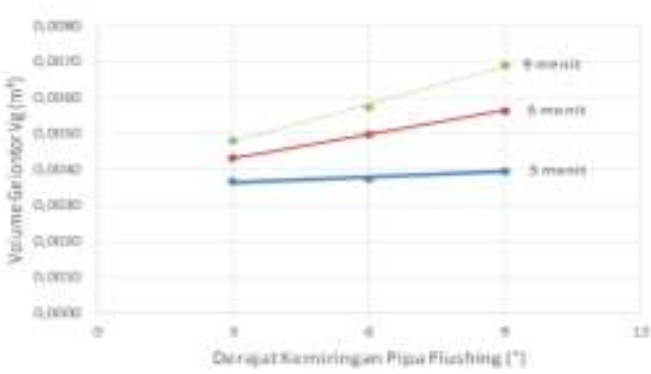

Gambar 10. Grafik hubungan antara kemiringan terhadap volume gelontor pada $Q_{1}=0,0030 \mathrm{~m}^{3} /$ dtk

Tabel 5 Hubungan antara kemiringan pipa terhadap volume gelontor. $\mathrm{Q}_{2}=0,0051$ $\mathrm{m}^{3} / \mathrm{dtk}$

\begin{tabular}{|c|c|c|c|}
\hline No & $\begin{array}{c}\text { Kemirneas Eiva } \\
\text { (V) }\end{array}$ & $\begin{array}{c}\text { Wakson } \\
\text { imesel) }\end{array}$ & Valume gelontex $\left.\mathrm{Vg}(\mathbf{m})^{\prime}\right)$ \\
\hline 1 & \multirow{3}{*}{3} & 3 & 0.0010 \\
\hline 2 & & 6 & 0.006 \\
\hline 3 & & 9 & 0.0054 \\
\hline 4 & \multirow{3}{*}{ a } & 3 & 0.0041 \\
\hline 3 & & 6 & 0.0053 \\
\hline 6 & & 9 & 0,0001 \\
\hline 7 & \multirow{3}{*}{9} & 3 & 00048 \\
\hline 1 & & 6 & 0.0053 \\
\hline 9 & & 9 & 0.0076 \\
\hline
\end{tabular}

Sumber:Hasil Perhitungan

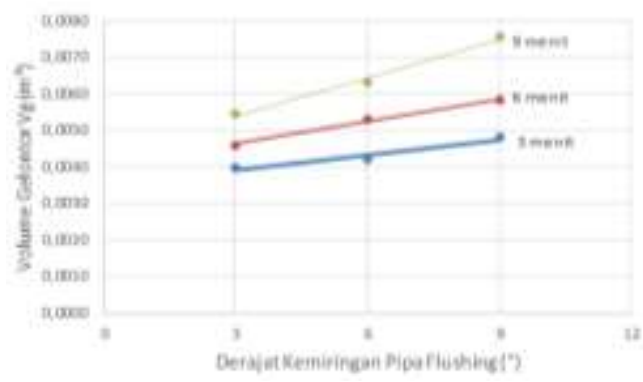


Gambar 11. Grafik kemiringan pipa flushing terhadap volume gelontor pada $\mathbf{Q}_{2}$

Tabel 6. Hubungan antara kemiringan pipa flushing (I) terhadap volume gelontor. $\mathrm{Q}_{3}$ $=0,0079 \mathrm{~m}^{3} / \mathrm{dtk}$

\begin{tabular}{|c|c|c|c|}
\hline No & 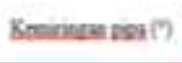 & $\begin{array}{l}\text { Tidat } \\
\text { pent }\end{array}$ & Voblue aricear $\mathrm{VI}_{\mathrm{I}}(\mathrm{m})$ ') \\
\hline 1 & \multirow{3}{*}{3} & 3 & 60041 \\
\hline 2 & & 6 & 60047 \\
\hline 3 & & 9 & 0.0059 \\
\hline 4 & \multirow{3}{*}{6} & 3 & 60045 \\
\hline 3 & & 6 & ecoss. \\
\hline 6 & & 9 & 0,0055 \\
\hline 7 & \multirow{3}{*}{9} & 3 & e.0054 \\
\hline 1 & & 6 & 0,0003 \\
\hline 3 & & 9 & $0.00 \mathrm{E}$ \\
\hline
\end{tabular}

Sumber:Hasil Perhitungan

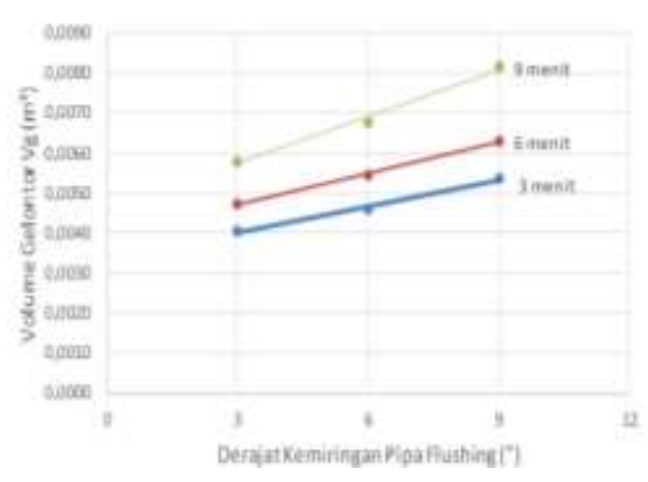

Gambar 12. Grafik hubungan kemiringan pipa terhadap volume gelontor pada $\mathbf{Q}_{3}$

Hubungan Antara Tekanan aliran terhadap Volume Gelontor (Vg).

Pengaruh hubungan tekanan aliran (P) dengan volume gelontor $\mathrm{Vg}$ (m3) menunjukkan bahwa semakin tinggi tekanan aliran (P) didalam pipa terlihat volume gelontor $\mathrm{Vg}(\mathrm{m} 3)$ yang terjadi juga semakin besar. Diperkirakan dipengaruhi oleh bertambahnya tekanan aliran yang cukup signifikan.
Tabel 7. Hubungan antara tekanan aliran (P) terhadap volume gelontor $\mathrm{Vg}(\mathrm{m} 3) . \mathrm{Q}_{1}$ $=0,003 \mathrm{~m}^{3} / \mathrm{dtk}$

\begin{tabular}{|c|c|c|c|}
\hline \multirow{2}{*}{ No } & Thanas alras (P) & \multirow{2}{*}{$\frac{\text { aszrucio }}{\text { inmos }}$} & \multirow{2}{*}{ 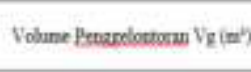 } \\
\hline & (ksame) & & \\
\hline 1 & \multirow{3}{*}{0.06420} & 1 & 0.0097 \\
\hline 2 & & 5 & 0.0043 \\
\hline 3 & & 9 & 00048 \\
\hline 4 & \multirow{3}{*}{0.06494} & 1 & 0.0091 \\
\hline 3 & & 8 & 0.0000 \\
\hline 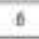 & & 5 & $0.005 t$ \\
\hline 7 & \multirow{3}{*}{0.06562} & 3 & 0.0040 \\
\hline 8 & & 5 & 00056 \\
\hline 9 & & 9 & 0.0069 \\
\hline
\end{tabular}

Sumber:Hasil Perhitungan

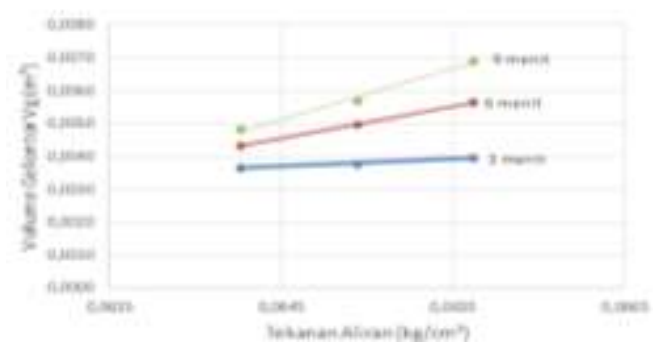

Gambar 13. Grafik hubungan antara tekanan aliran (P) terhadap volume penggelontoran untuk $Q_{1}$

Tabel 8. Hubungan antara tekanan aliran (P) terhadap volume penggelontoran $\mathrm{Vg}$ (m3). $\mathrm{Q}_{2}=0,0051 \mathrm{~m}^{3} / \mathrm{dtk}$

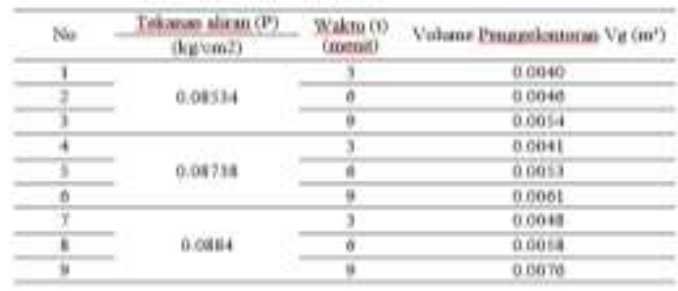

Sumber:Hasil Perhitungan
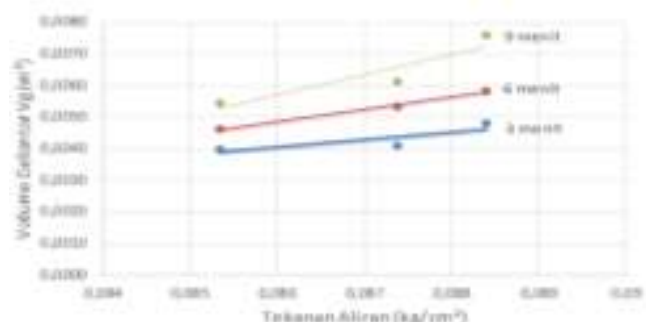

Gambar 14. Grafik hubungan antara tekanan aliran (P) terhadap volume penggelontoran untuk $\mathbf{Q}_{2}$. 
Tabel 9. Hubungan antara tekanan aliran (P) terhadap volume penggelontoran. $\mathrm{Q}_{3}$ $=0,0079 \mathrm{~m}^{3} / \mathrm{dtk}$

\begin{tabular}{|c|c|c|c|}
\hline \multirow{2}{*}{ No } & Tdianes ufrae (P) & \multirow{2}{*}{$\frac{\text { Whatro (t) }}{\text { (ment) }}$} & \multirow{2}{*}{$\begin{array}{c}\text { Volume Rengyelortoras Va } \\
\left(\mathrm{m}^{2}\right)\end{array}$} \\
\hline & $\log (\mathrm{cm})$ & & \\
\hline 1 & \multirow{3}{*}{0.13464} & 3 & 0.0041 \\
\hline 2 & & 6 & 0.0047 \\
\hline 3 & & 9 & 0.0659 \\
\hline 4 & \multirow{3}{*}{0.13634} & 3 & 0.0046 \\
\hline 5 & & 6 & 0.0655 \\
\hline 6 & & 9 & 0.0067 \\
\hline 7 & \multirow{3}{*}{0.13702} & 3 & 0.0054 \\
\hline 8 & & 6 & 0.0063 \\
\hline 9 & & 9 & 0.0082 \\
\hline
\end{tabular}

Sumber:Hasil Perhitungan

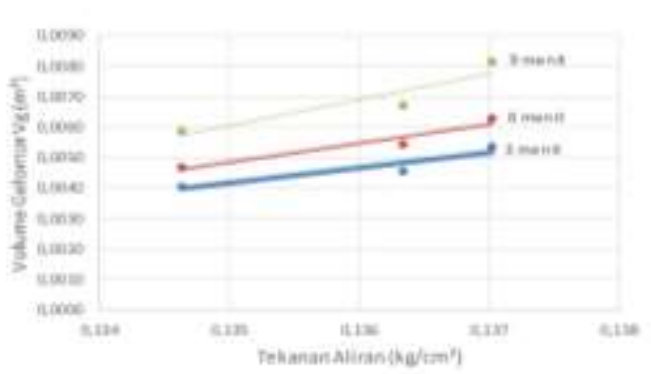

Gambar 15. Grafik hubungan antara tekanan aliran (P) terhadap volume penggelontoran untuk $\mathbf{Q}_{3}$

\section{Hubungan Antara Debit Aliran terhadap Volume Gelontor (Vg)}

Berdasarkan hasil data data yang diperoleh maka dapat disimpulkan bahwa debit aliran (Q) adalah salah satu faktor yang mempegaruhi jumlah sedimen yang tergelontor dalam proses pengurasan metode flushing conduit.

Tabel 10. Hubungan antara Debit aliran (Q) terhadap volume gelontor $(\mathrm{Vg})$ untuk kemiringan $3^{\circ}$

\begin{tabular}{|c|c|c|c|c|}
\hline No & & athat id & 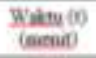 & Vohmen arimex $V_{t}\left(m^{\prime}\right)$ \\
\hline 1 & \multirow{3}{*}{ Qt } & \multirow{3}{*}{60006} & 3 & 00037 \\
\hline 2 & & & 5 & 00043 \\
\hline 3 & & & $\Rightarrow$ & 00041 \\
\hline 4 & \multirow{3}{*}{ Qt } & \multirow{3}{*}{50051} & 3 & 00046 \\
\hline 3 & & & 8 & $6004 h$ \\
\hline e & & & 7 & 00054 \\
\hline$?$ & \multirow{3}{*}{$Q$} & \multirow{3}{*}{0.0078} & 3 & 90041 \\
\hline 1 & & & 8 & 00047 \\
\hline 9 & & & , & 0005 \\
\hline
\end{tabular}

Sumber:Hasil Perhitungan

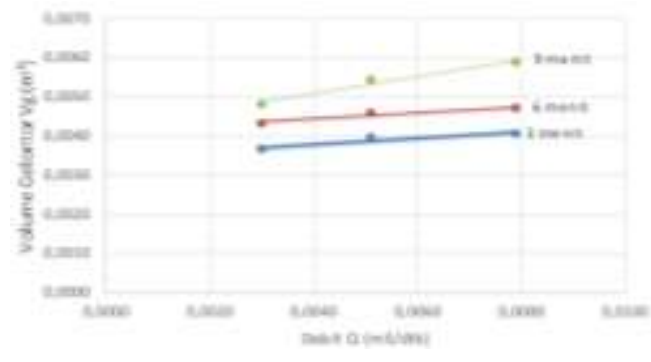

Gambar 16. Grafik hubungan antara Debit aliran (Q) terhadap volume gelontor (Vg) untuk kemiringan $3^{\circ}$

Tabel 11. Hubungan antara Debit aliran (Q) terhadap volume gelontor ( $\mathrm{Vg})$ untuk kemiringan $6^{\circ}$

\begin{tabular}{|c|c|c|c|c|}
\hline No & & $\frac{\ln a}{45}(Q)$ & $\begin{array}{l}\text { Thath (t) } \\
\text { (monit) }\end{array}$ & Volam ablesar $V_{z}(m)$ ) \\
\hline 1 & \multirow{3}{*}{ Q! } & \multirow{3}{*}{0.0030} & 3 & 00001 \\
\hline 2 & & & 8 & 0000 \\
\hline 3 & & & 9 & 0065 \\
\hline 4 & \multirow{3}{*}{$Q$} & \multirow{3}{*}{00001} & 3 & 0004 \\
\hline 5 & & & 6 & 0.5053 \\
\hline 8 & & & 9 & 00661 \\
\hline 7 & \multirow{3}{*}{ Q3 } & \multirow{3}{*}{ expos } & 3 & ocoues \\
\hline 3 & & & 5 & 00005 \\
\hline 9 & & & 9 & 00067 \\
\hline
\end{tabular}

Sumber:Hasil Perhitungan

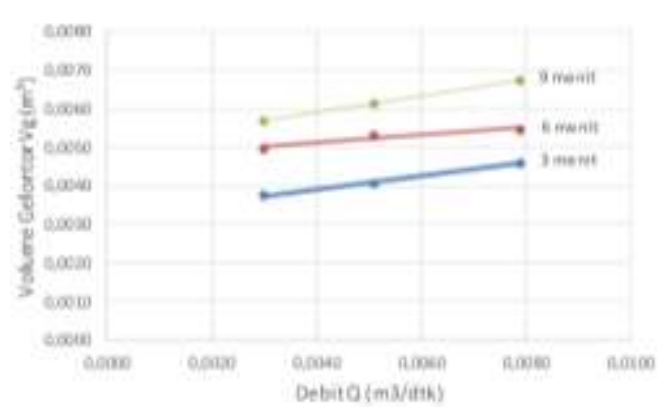

Gambar 17. Grafik hubungan antara Debit aliran (Q) terhadap volume gelontor (Vg) untuk kemiringan $6^{\circ}$

Tabel 12. Hubungan antara Debit aliran (Q) terhadap volume gelontor $(\mathrm{Vg})$ untuk kemiringan $9^{\circ}$

\begin{tabular}{|c|c|c|c|c|}
\hline $\mathrm{No}$ & & ing & $\frac{\text { Thals }}{(m e x t)}$ & 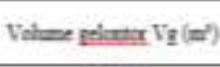 \\
\hline 1 & \multirow{3}{*}{ Q1 } & \multirow{3}{*}{0,0030} & 3 & 60040 \\
\hline 2 & & & 6 & 0.0056 \\
\hline 3 & & & 9 & 0.0069 \\
\hline 4 & \multirow{3}{*}{$Q 2$} & \multirow{3}{*}{0.0051} & 3 & 0.0048 \\
\hline 5 & & & 6 & 20058 \\
\hline 6 & & & 9 & 00076 \\
\hline 7 & \multirow{3}{*}{ Qs } & \multirow{3}{*}{0.0079} & 3 & 0.0054 \\
\hline 8 & & & 5 & 0.0063 \\
\hline 9 & & & 9 & 0,0002 \\
\hline
\end{tabular}

Sumber:Hasil Perhitungan 


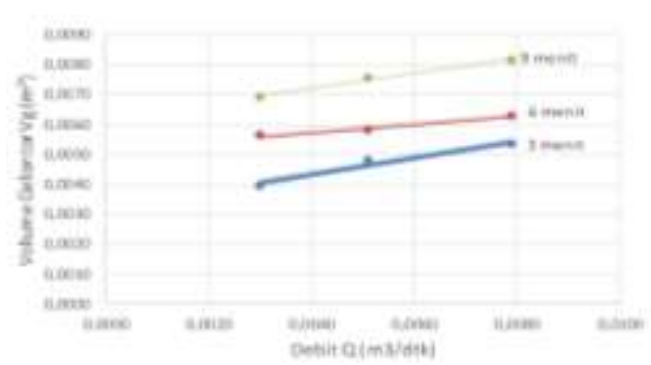

Gambar 18. Grafik hubungan antara Debit aliran (Q) terhadap volume gelontor $(\mathrm{Vg})$ untuk kemiringan $9^{\circ}$ PENUTUP

\section{Kesimpulan}

1) Semakin miring Pipa flushing conduit maka volume penggelontoran $\mathrm{Vg}(\mathrm{m} 3)$ semakin besar dimana volume penggelontoran tertinggi berada pada kemiringan $9^{\circ}$.

2) Semakin Besar tekanan aliran yang terjadi di dalam pipa juga mempengaruhi besarnya volume penggelontoran sedimen (Vg) (m3).

3) Lamanya waktu yang digunakan dalam proses penggelontoran juga mempengaruhi besarnya volume sedimen yang tergelontor.

\section{Saran}

1) Penelitian tentang penggelontoran sedimen dengan sistem flushing conduit perlu dikembangkan lebih lanjut dengan menambahkan beberapa variasi model lainnya untuk mendapatkan hasil yang lebih baik dan akurat.

2) Untuk penelitian selanjutnya sudut kemiringan pipa flushing conduit perlu ditambah untuk memperoleh data yang lebih banyak sehingga bisa menjadi perbandingan terhadap penelitianpenelitian selanjutnya.

\section{DAFTAR PUSTAKA}

Alimuddin L,Aisyah. (2012). Pendugaan Sedimentasi pada DAS Mamasa di Kab. Mamasa Propinsi Sulawesi Selatan. Fakultas Pertanian Unhas. Makassar

Amrullah. (2010). Studi Kinerja Flushing Conduit Sebagai Alat Penguras Endapan Sedimen Muara Dengan Experimen Laboratorium. Program Pascasarjana Universitas hasanuddin. Makassar

Amrullah. Afni Mansyur Nur, dan Nurlia. (2017). Studi Pengaruh Spasi Lubang Flushing Conduit Terhadap Volume Gelontor Pada Sedimen Di Waduk. (Uji Eksperimental). Universitas Muhammadiyah Makassar.

Amrullah. Dudung Massora Alfin Eko, dan Syakir Muhammad. (2017). Studi Pengaruh Debit Penghisapan Flushing Conduit Terhadap Penggelontoran Sedimen Di Waduk (Uji Eksperimental). Universitas Muhammadiyah Makassar.

Amrullah. Mardiana, dan Wahyuni Sri. (2017). Studi Pengaruh Diameter Lubang Flushing Conduit Terhadap Penggelontoran Sedimen Di Waduk (Uji Eksperimental). Universitas Muhammadiyah Makassar.

Amrullah. Nisa Husnun, dan Jaya T Hendra. (2017). Studi Pengaruh 
Ketebalan Sedimen pada Flushing Conduit Terhadap Volume Penggelontoran dengan Material Dasar Pasir Halus Di Waduk (Uji Eksperimental). Universitas Muhammadiyah Makassar.

Asdak, Chay. (2010). Hidrologi dan pengelolaan Daerah Aliran Sungai:Edisi Revisi Kelima. Yogyakarta: Gadjah Mada Press Yogyakarta

Biksono, Damawidjaya. (2006). Karakteristik Dan Visualisasi Aliran Dua Fasa Pada Pipa Spiral. Jurusan Teknik Mesin Fakultas Teknik. Cimahi-Bandung

Hakim, Siti Riskayanti. (2015). Studi Laju Sedimentasi Waduk Bili-Bili Pasca Pengembangan Bangunan Penahan Sedimen. Fakultas Teknik Universitas Hasanuddin. Makassar

Krisetyana, Hari. (2008). Tingkat Efisiensi Penggelontoran Endapan Sedimen Di Waduk PLTA PB. Sudirman. Program Pasca Sarjana Megister Teknik Sipil Universitas Diponegoro. Semarang

Hakim, Fajar Aldoko. (2016). Analisis Sebaran Sedimendan Efektifitas Tampungan Menggunakan Teknik Interpolasi Ruang (Studi Kasus Penggelontoran Waduk Wlingi Dan Waduk Lodoyo. Fakultas Teknik Universitas Brawijaya. Malang

Lubis, Astika Murni. (2016). Analisis Sedimentasi Sungai Way Besar. Fakultas Teknik Universitas Lampung

Suroso. Dan Widiyanto, Wahyu. (2009). Model Pengendalian Sedimentasi Waduk Mrica Dengan Fluidasi.
Program Studi Teknik Sipil Unsoed. Purwokerto Indonesia

Sinatala, Arsyad. (2010). Edisi kedua: konservasi tanah dan air. Bogor: Institut Pertanian Bogor

Thaha, A. (2006). Sistem Fluidasi Untuk Rekayasa Pemeliharaan Alur. Universitas Gadjah Mada. Yogyakarta

Triatmojo B, 1993. Hidraulika 1. Beta Ofset. Yogyajarta

Triatmojo B, 1993. Hidraulika 11. Beta Ofset. Yogyakarta 